\title{
Vol. 82 No. 4 September 2017
}

\section{CYTOLOGIA}

International Journal of Cytogenetics and Cell Biology

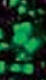

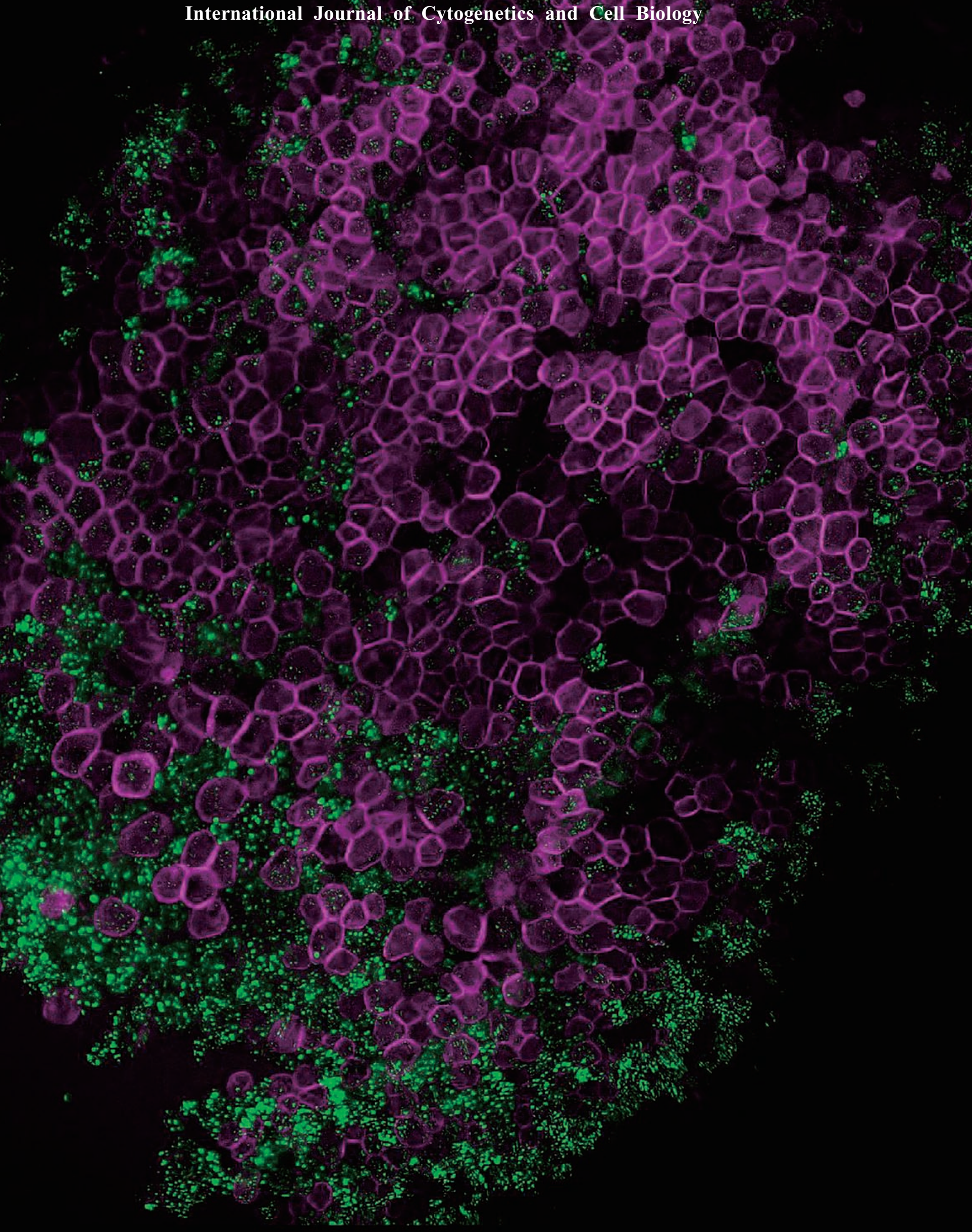




\title{
Technical Note:
}

\section{Easy and Rapid Induction of Vascular Cells by VISUAL}

\author{
Yuki Kondo*, Atsuki Suguchi and Hiroo Fukuda \\ Department of Biological Sciences, Graduate School of Science, The University of Tokyo, \\ 7-3-1 Hongo, Bunkyo-ku, Tokyo 113-0033, Japan
}

Received August 30, 2017; accepted September 6, 2017

The vascular system is composed of xylem and phloem tissues intervened by cambial cells, which undergo cell division to supply vascular cells. Since vasculature is located deep inside the plant body, it is quite difficult to monitor the differentiation process. To overcome such difficulty, several xylogenic cultures have long been used for analyzing xylem development. However, no efficient system for phloem differentiation has been developed, which prevents the easy and rapid investigation of phloem development. Recently, we established a new tissue culture system for vascular cell differentiation named VISUAL (Kondo et al. 2014, 2015, 2016). Here we examined phloem differentiation after VISUAL induction with the use of the phloem-specific marker SEOR1pro: SEOR1-YFP (Froelich et al. 2011).

Xylem (magenta) and phloem (green) differentiation appeared ectopically in cotyledons, indicating that VISUAL can generate a large number of phloem cells as well as xylem cells within only four days. Indeed, we revealed a co-expression network for early and late stages of phloem differentiation with the VISUAL system
(Kondo et al. 2016). Therefore, VISUAL is a powerful tool for analyzing phloem development and will be useful for understanding the multipotency of cambial cells.

\section{References}

Froelich, D. R., Mullendore, D. L., Jensen, K. H., Ross-Elliott, T. J., Anstead, J. A., Thompson, G. A., Pélissier, H. C. and Knoblauch, M. 2011. Phloem ultrastructure and pressure flow: Sieve-Element-Occlusion-Related agglomerations do not affect translocation. Plant Cell 23: 4428-4445.

Kondo, Y., Fujita, T., Sugiyama, M. and Fukuda, H. 2015. A novel system for xylem cell differentiation in Arabidopsis thaliana. Mol. Plant 8: 612-621.

Kondo, Y., Ito, T., Nakagami, H., Hirakawa, Y., Saito, M., Tamaki, T., Shirasu, K. and Fukuda, H. 2014. Plant GSK3 proteins regulate xylem cell differentiation downstream of TDIF-TDR signalling. Nat. Commun. 5: 3504.

Kondo, Y., Nurani, A. M., Saito, C., Ichihashi, Y., Saito, M., Yamazaki, K., Mitsuda, N., Ohme-Takagi, M. and Fukuda, H. 2016. Vascular cell induction culture system using Arabidopsis leaves (VISUAL) reveals the sequential differentiation of sieve elementlike cells. Plant Cell 28: 1250-1262.

\footnotetext{
*Corresponding author, e-mail: p@bs.s.u-tokyo.ac.jp

DOI: $10.1508 /$ cytologia. 82.335
} 